\title{
THE TOPOGRAPHY CHANGE OF ELECTRODE TIPS AT RESISTANCE WELDING OF DEEP DRAWN STEEL DC05+ZE
}

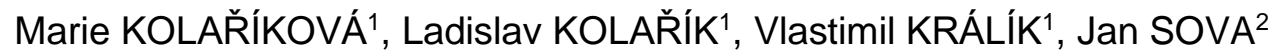 \\ ${ }^{1}$ CTU - Czech Technical University of Prague, Faculty of Mechanical Engineering, Technická 4, Prague, \\ Czech Republic, EU, marie.kolarikova@fs.cvut.cz \\ ${ }^{2}$ Workswell s.r.o., U Albrechtova vrchu 1182/12, Prague, Czech Republic, EU, jan.sova@workswell.cz
}

https://doi.org/10.37904/metal.2020.3529

\begin{abstract}
During resistance welding, the electrode tips are significantly worn. The amount of wear is strongly dependent on the welded material, the surface treatment of the welded sheet, the thickness of the surface treatment, the welding parameters and, last but not least, especially on the number of performed welds. The paper describes the change in topography (RedLux optical profilometer) and roughness (Mitutoyo roughness tester) of the contact surface of the electrode tip during the wear process (thus depending on the number of welds performed). It also deals with the change of welding parameters due to the change in the size of the actual contact area. Deep drawing steel DC05 + ZE (EN 10152) electrolytically coated with Zn (with a total thickness $\mathrm{h}=0.7 \mathrm{~mm}$ and a zinc coating thickness of $4.5 \mu \mathrm{m}$ ) was used as the experimental material. The roughness of the contact surface increases evenly. It reaches a maximum after about 100 welds and then decreases. The welding current also increases evenly. It is kept constant between 200 and 350 welds and then grows again.
\end{abstract}

Keywords: Wear of electrode tips, RedLux, Topography of contact area, Roughness, Change of welding parameters

\section{INTRODUCTION}

Electrode wear during resistance welding occurs from the first weld. Several wear mechanisms can be observed. These are, in particular, the alloying of the electrode tip with elements made of welded sheet metal (or from the surface treatment), deformation of the electrode tip, formation of a hole on the contact surface of the electrode and cavitation. Due to the different coefficients of thermal expansion of the electrode and the welded material, brittle fracture occurs in the electrode well. This leads to the material being pulled out of the contact surface of the electrode [1]. The mushrooming effect increases the set parameters, which again leads to a larger mushroom effect [2]. The electrode tip types (B-nose and E-nose) did not affect fatigue strength of spot welds [3]. The service life of the electrode can be increased (when welding steel sheets) by using galvanic coatings with higher iron content (approx. 10\% and more) [4]. In the case of a Zn coating, the front temperature of the electrode should not be higher than the melting point of $\mathrm{Zn}$. Numerical models predict the rate of penetration of $\mathrm{Zn}$ into $\mathrm{Cu}$ up to 500 times higher than the rate of diffusion in the solid state [5]. After alumina welding, positive effect of higher electrode roughness can be used which allowing the destruction of the oxide layer on the surface of the material. As a result, however, the heat of resistance is reduced and thus the shear strength is reduced [6]. Defects in welded joints can occur during the life cycle of the electrodes. One way to $100 \%$, non-destructive on-line control is to measure dynamic resistance [7] or thermography. To set up the inspection process, it is also necessary to describe external influences such as the morphology of the bearing surfaces of the electrode tips. The aim of the paper is to describe the influence of the number of spot welds on the roughness and topography of the contact surface of the electrode tip and the related change of welding parameters. 


\section{MATERIALS}

As base material is used deep-drawn steel DC05 (EN 10152), electrolytically coated, with a total thickness $\mathrm{h}=0.7 \mathrm{~mm}$ and a zinc coating thickness of $4.5 \mu \mathrm{m}$. The chemical composition and mechanical properties are given in Table 1. Used material of electrode tips were A2/2 - CuCr1Zr. Chemical composition of the cap is: $\mathrm{Cu}=98.98 \%, \mathrm{Cr}=0.9 \%, \mathrm{Zr}=0.12 \%$.

Table 1 Chemical composition and mechanical properties of steel DC05 + ZE

\begin{tabular}{|c|c|c|c|c|c|c|c|c|}
\hline $\mathbf{C}[\%]$ & Mn [\%] & P [\%] & S [\%] & Si [\%] & Ti [\%] & $\operatorname{Re}[\mathrm{MPa}]$ & $\boldsymbol{R m}[\mathrm{MPa}]$ & $\mathbf{A}_{\mathbf{8 0}}$ \\
\hline 0.02 & 0.25 & 0.02 & 0.02 & 0.02 & 0.3 & $\max 180$ & $270-350$ & 41 \\
\hline
\end{tabular}

\section{EQUIPMENT}

Middle frequency direct current (MFDC) source PMS 11-4 (DALEX) was used for welding, with use of electrode tips type 39D 1978-2 used in automotive. The S.E.R. system was used to control the welding process and monitor the welding parameters. For ultrasonic testing (UT), an Olympus Epoch 650 series instrument with a V2450 probe was used for spot welds with a $20 \mathrm{MHz}$ water transfer, inverter diameter $4 \mathrm{~mm}$. A Mitutoyo Surftest SJ-301 roughness meter was used to measure roughness. For further analysis of the contact area, a 4-axis optical profilometer from RedLux (RedLux Ltd., Southampton, UK) was used, which is shown in Figure 1. It consists of two sliding and two rotary axes, which use air bearings to achieve higher accuracy of movement. The rotary axes move with the sample and the sliding axes move with the sensor. All axes use optical position sensors and linear motors. The sensor is a spot confocal sensor, the principle of which is based on a color defect of the lens (chromatic aberration) and is used to very accurately measure the distance from the measured object. According to the values specified by the manufacturer, the linear axes have a resolution of $100 \mathrm{~nm}$, the rotary axes 10 ". The resolution of the point confocal sensor specified by the manufacturer is $20 \mathrm{~nm}$. The profilometer records the position of individual surface points with a certain frequency. The frequency of point scanning can be set in both the circumferential and longitudinal directions.

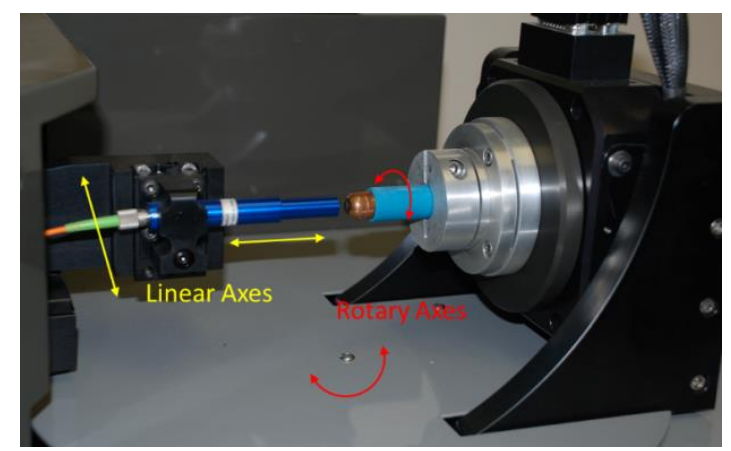

Figure 1 The detail of optical profilometer RedLux

\section{EXPERIMENT}

Samples measuring $350 \times 500 \mathrm{~mm}$ were used for the experiment, on which rows of spot welds were made in order to wear the welding caps. The welding parameters were chosen so as to create a satisfactory welded joint with regard to the requirements of the ČSN EN ISO 14373 standard, i.e. parameters from the area of welding $(I=6.5 \mathrm{kA}, \mathrm{t}=200 \mathrm{~ms}, \mathrm{P}=2.0 \mathrm{kN})$. The set welding parameters were intentionally not regulated to determine the effect of topography and the size of the actual contact area of the electrode tips.

A set of worn electrode tips was made, with defined wear. A different number of welds was created with each pair of tips (upper and lower electrode), with the repeating parameters mentioned above. The selected 
numbers of welds for wear were: $10,25,50,75,100,150$ and 200. In the automotive industry, after 150 welds, electrode tips are usually preventively dressed. The resulting quality of the joint was checked by ultrasonic testing (UT) for the presence of internal or structural defects. The sample echograms showed a linearly decreasing tendency of the end echoes with a sufficient number of echoes to represent a satisfactory welded joint. All samples passed.

Roughness was measured on the worn contact areas of the electrodes. Each worn tip was measured a total of 5 times over the entire contact area. Between individual measurements, the sample was always rotated by about $30^{\circ}$. The surface topography was always measured at the lower electrode. The measured data from individual electrode tips (with different degrees of wear) were compared with the original state. An area with a diameter of $7 \mathrm{~mm}$, which includes the whole wear area, was chosen for evaluation (Figure 2). On this circular surface the percentage of the surface where the loss and increase in material was evaluated.

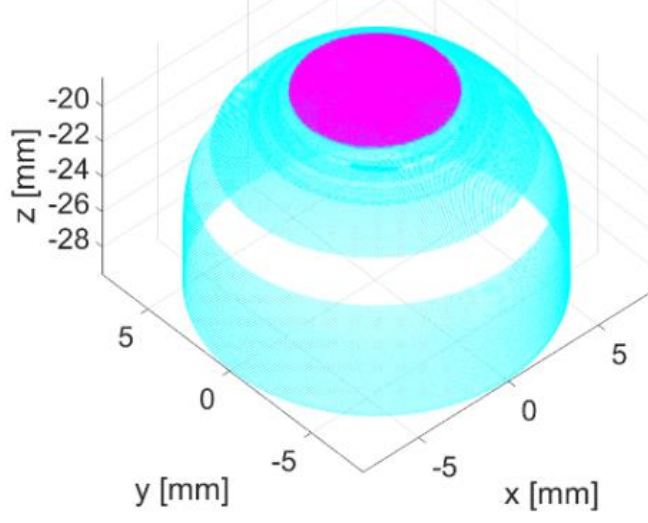

Figure 2 Selected area (pink colour, diameter $=7 \mathrm{~mm}$ ) for wear evaluation

\section{RESULTS AND DISCUSSION}

Dependence of the roughness of the contact surface of the electrode tip on the number of performed welds is in Figure 3. The graph shows the trend of increasing roughness from values around $\mathrm{Ra}=0.5 \mu \mathrm{m}$ to values exceeding $\mathrm{Ra}=1.5 \mu \mathrm{m}$ after 100 welds. With a larger number of welds, the roughness subsequently stabilizes at an average value of $\mathrm{Ra}=1 \mu \mathrm{m}$.

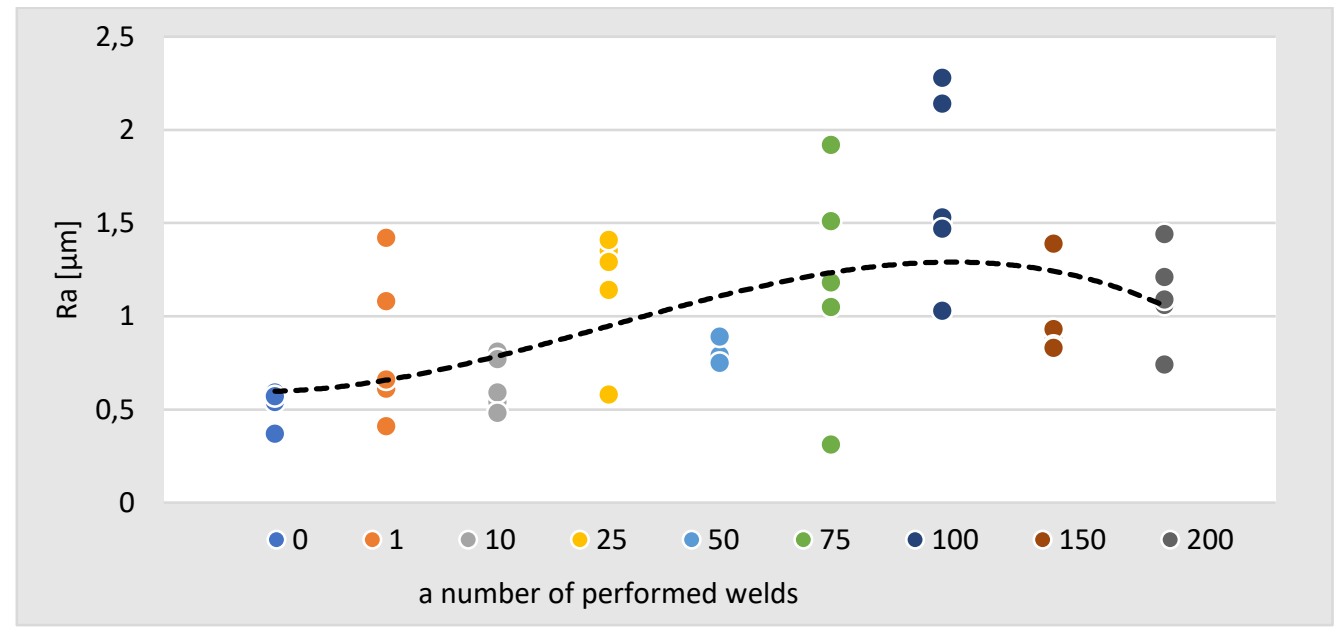

Figure 3 Dependence of the roughness of the contact surface of the electrode tip on the number of performed welds 


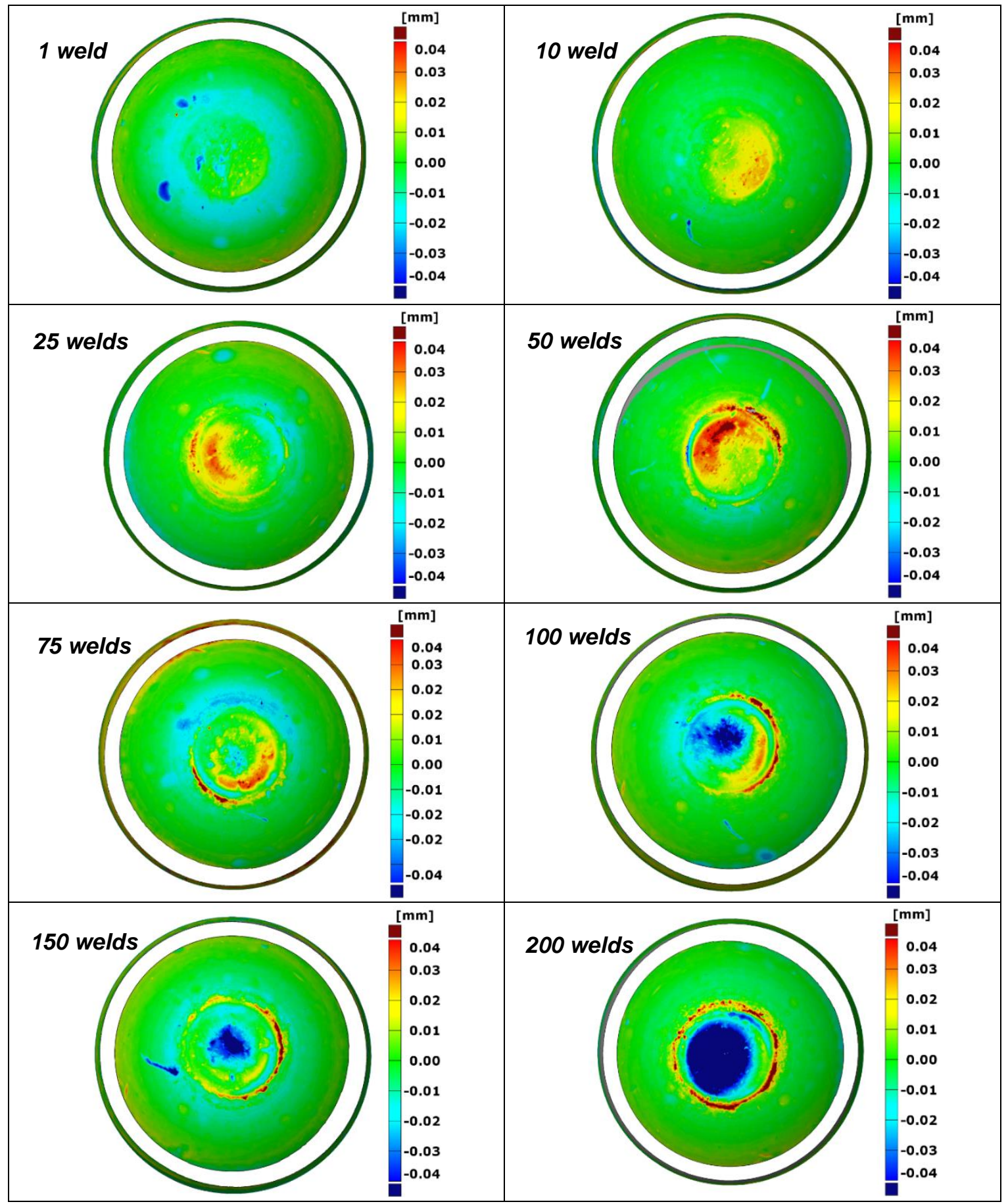

Figure 4 Colour map of deviations of measured data from the original state

Figure 4 shows a color map of the deviations of the individual worn electrode tips compared to the original state. Blue means that the measured data is below the original surface (i.e. deformed or torn material), red color means that the measured data protrude above the original surface (i.e. adhered material from the sheet metal surface). After the first weld, only the imprint (deformation) of the electrode tip occurs. After 10 welds, a certain increase in volume can already be seen on the surface of the electrode (due to the higher temperature, $\mathrm{Zn}$ diffuses into the electrode material, and a $\mathrm{Cu}$ and $\mathrm{Zn}$ alloy begins to form on the contact surface). After 75 welds, a crater is formed in the central area of the contact surface after the torn material. A ring of deposited material is formed around the perimeter of the contact surface (adhesive-diffusion transfer of $\mathrm{Zn}$ from the sheet coating). As the number of welds increases, both the crater in the central region and the ring of deposited 
material around the perimeter become more pronounced. The above color maps from Figure 4 show the effect of inaccurate sample placement before welding. The obliquely placed sheet metal deforms (pushes) the contact surface of the electrode tip on one side and materials are applied on the other half due to diffusion.

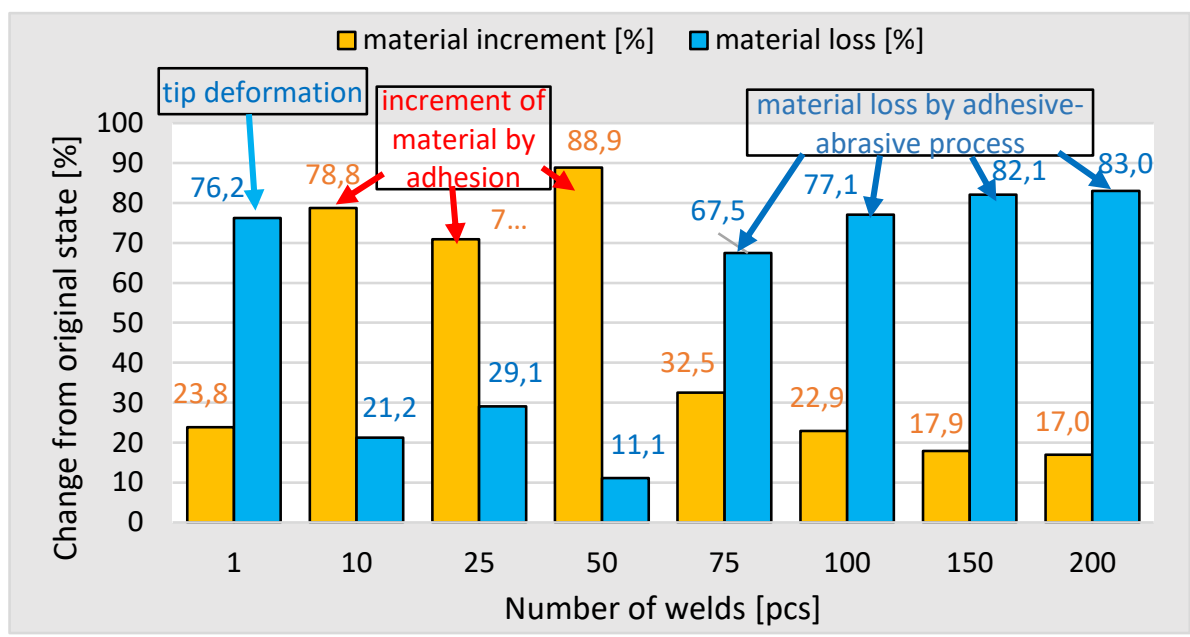

Figure 5 Change in the topography of the contact surface of the electrode tip depending on the number of welds performed

Figure 5 shows the percentage change from the original state (Figure 4 - green color). It can be seen from the graph that the electrode tip is deformed during the first weld (approx. $75 \%$ of the evaluated area). This strengthens the contact area. As mentioned above, with a higher number of welds, the coating material adheres to the contact surface (for 50 welds, the adhered material covers $89 \%$ of the evaluated area). This leads to an increase in its diameter by $2 \%$ (from $5 \mathrm{~mm}$ to $6 \mathrm{~mm}$ ) and to a change in the chemical composition at the surface. This mechanism is applied up to the number of welds 50 . Then the wear process is changed and the adhesive-abrasive mechanism begins to prevail relatively quickly. The material is torn out and a depression is formed in the center of the contact surface (Figure 5 - 200 welds). For 200 welds, the depression already covers $83 \%$ of the evaluated area.

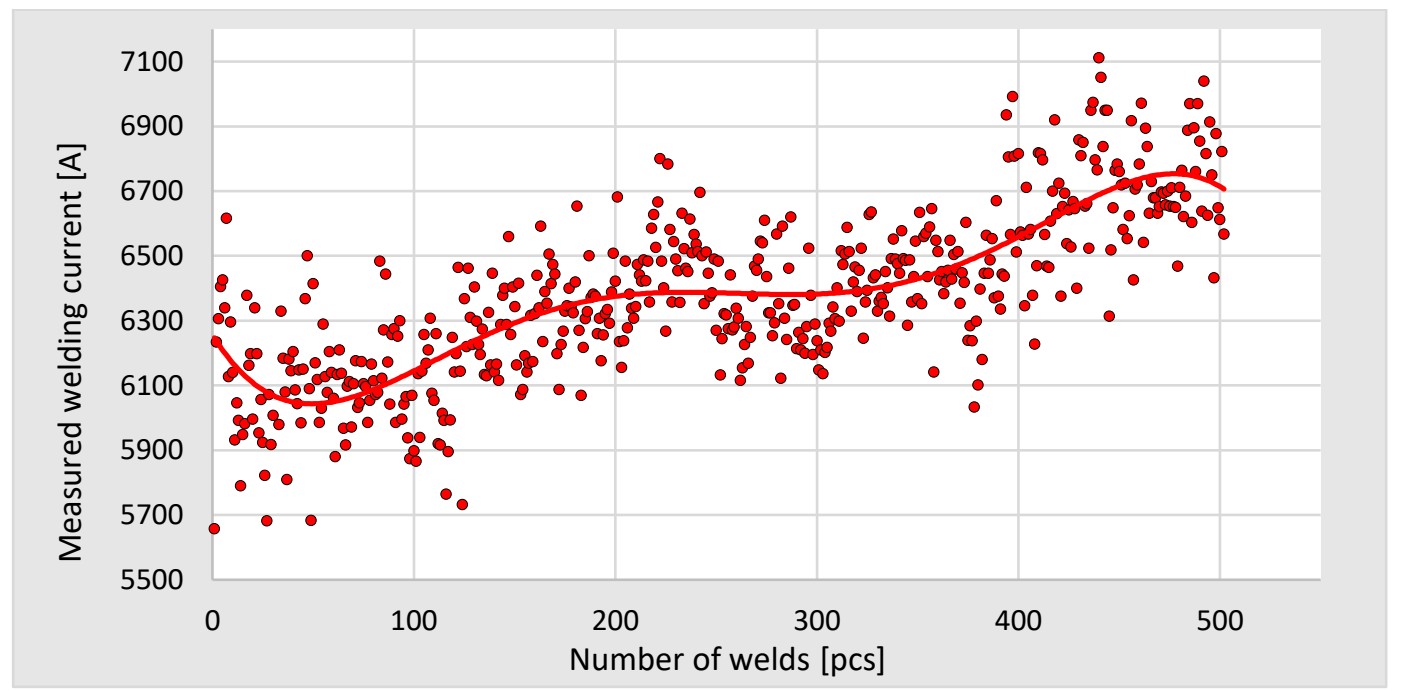

Figure 6 Change in the amount of welding current depending on the number of welds performed

Figure 6 shows the behavior of the welding current during the life cycle of the welding tip. The welding current was set at $6500 \mathrm{~A}$. Nevertheless, the first weld on the unworn tip was welded with a current of $6250 \mathrm{~A}$. Up to 
the number of welds 50 , where the mechanism of adhesive and diffusion material transfer predominates (increase of contact area diameter and material volume), the welding current decreases. At 50 welds, it drops by about $200 \mathrm{~A}(3.2 \%)$. Then the welding current increases evenly up to the number of performed welds 200 . The increase of current is on average $350 \mathrm{~A}(5.6 \%)$. Up to 350 welds, the welding current does not change and remains around $6400 \mathrm{~A}$. Above 350 welds, the welding current increases further to values around $6750 \mathrm{~A}$. The total maximum change in welding current is $700 \mathrm{~A}(11.2 \%)$. At these values, there has already been excessive spattering of the material.

\section{CONCLUSION}

The topography of the contact surface is an important parameter in the life cycle of the electrode tip. An experiment was designed to monitor the change in topography depending on the number of welds performed. The welded material was deep-drawn steel DC05 + ZE. An MFDC welding source with an electrode cap type 39D 1978-2 was used. The following conclusions can be drawn from the results:

- $\quad$ the roughness of the contact surface of the electrode tip increases with the number of performed welds from the initial value $\mathrm{Ra}=0.5 \mu \mathrm{m}$ to the average value $\mathrm{Ra}=1.5 \mu \mathrm{m}$ after 100 welds, then it stabilizes at the average value $\mathrm{Ra}=1 \mu \mathrm{m}$.

- the geometry of the contact surface also changes with the number of performed welds. After 75 welds, a shallow depression begins to form in the middle of the contact area. The diameter of the contact area increases by $1 \mathrm{~mm}$. After 200 welds, there is a depression over the entire original contact area.

- $\quad$ the welding current first decreases (up to 50 welds) and then increases evenly up to 500 performed welds, except for the range between 200 and 300 welds where it is constant.

\section{ACKNOWLEDGEMENTS}

\section{This research was been supported by the project TRIO No. FV10757 „Thermovision system for} non-destructive testing of weld joints“, financed by MPO ČR.

\section{REFERENCES}

[1] LANG, B., SUN, D.Q, LI, G.Z., ZHU, B.Q. Electrode Degradation in Resistance Spot Welding of Magnesium Alloy. (In:) ISIJ International [online]. 2009. vol. 49, No. 11, pp 1744 - 1748 [wiewed 2020-04-28].

[2] CHARDE, N. Effects of Electrode Deformation on Carbon Steel Weld Geometry of Resistance Spot Welding. (In:) IJAITI [online]. 2012. vol. 1, No. 5 [wiewed 2020-05-03].

[3] KANG, H.T., ACCORSI, I., PATEL, B., PAKALNINS, E. Fatigue performance of resistance spot welds in three sheet stack-ups. (In:) Procedia Engineering 2 [online]. 2010, pp 129 - 138 [wiewed 2020-04-29]. Available from: DOI: 10.1016/j.proeng.2010.03.014.

[4] HU, X., ZOU, G., DONG, S.J., LEE, M.Y., JUNG, P.J., ZHOU, Y. Effects of Steel Coatings on Electrode Life in Resistance Spot Welding of Galvannealed Steel Sheets. (In:) Materials Transactions [online]. 2010. vol. 51, No. 12, pp 2236 - 2242 [wiewed 2020-04-29]. Available from: DOI: 10.2320/matertrans.M2010239.

[5] BABU, S.S., SANTELLA, M.L. and PETERSON, W. Modeling Resistance Spot Welding Electrode Life. (In:) United States: N. p., 2004. Web. [wiewed 2020-05-02]. Available from: http://citeseerx.ist.psu.edu/viewdoc/download?doi=10.1.1.544.8181\&rep=rep1\&type=pdf

[6] HYEONGGEUN, J., DONGCHEOL, K., MUNJIN, K., JUNHONG, P., YOUNG-MIN, K. Effects of Surface Roughness and Force of Electrode on Resistance Spot Weldability of Aluminum 6061 Alloy. (In:) Applied Sciences [online]. 2019. vol. 9, pp 3958 - 3972 [wiewed 2020-05-14]. Available from: DOI: 10.3390/app9193958.

[7] SUMMERVILLE, C. D. E., ADAMS, D., COMPSTON, P., DOOLAN, M. Process Monitoring of Resistance Spot Welding Using the Dynamic Resistance Signature. (In:) Welding Journal [online]. 2017, vol. 96, November, pp. 403-412 [wiewed 2019-03-29]. 